\title{
antioxidants
}

ISSN 2076-3921

www.mdpi.com/journal/antioxidants

Article

\section{Modelling Extraction of White Tea Polyphenols: The Influence of Temperature and Ethanol Concentration}

\section{Sara Peiró ${ }^{1,2,3}$, Michael H. Gordon ${ }^{4}$, Mónica Blanco ${ }^{5}$, Francisca Pérez-Llamas ${ }^{6}$, Francisco Segovia ${ }^{3}$ and María Pilar Almajano ${ }^{3, *}$}

1 Department of Health Microbiology and Parasitology, Faculty of Pharmacy, Barcelona University, Avenue Joan XXIII s/n, 08028 Barcelona, Spain; E-Mail: sara.peiro@yahoo.es

2 IRIS-Innovació I Recerca Industrial i Sostenible, Avda. Carl Friedrich Gauss nº 11 , 08860 Barcelona, Spain

3 Chemical Engineering Department, Technical University of Catalonia, Avda Diagonal 647, 08028 Barcelona, Spain; E-Mail: segoviafj@gmail.com

4 Department of Food and Nutritional Science, University of Reading, Whiteknights, P.O. Box 226, Reading RG6 6AP, UK; E-Mail: m.h.gordon@reading.ac.uk

5 Department of Applied Mathematics III, Technical University of Catalonia, ESAB, Campus del Baix Llobregat, Esteve Terradas 8, 08860 Barcelona, Spain; E-Mail: monica.blanco@upc.edu

6 Department of Physiology and Pharmacology, School of Biology, University of Murcia, Campus de Espinardo, 30100 Murcia, Spain; E-Mail: frapella@um.es

* Author to whom correspondence should be addressed; E-Mail: m.pilar.almajano@upc.edu; Tel.: +34-934-016-686.

External Editors: Maria G. Miguel and João Rocha

Received: 2 July 2014; in revised form: 29 July 2014 / Accepted: 30 September 2014 /

Published: 21 October 2014

\begin{abstract}
The optimization of the extraction of natural antioxidants from white tea has fostered intensive research. This study has investigated the effects of ethanol-water mixtures, temperature and time on the extraction of polyphenols and antioxidant components from white tea. The response surface methodology was applied to identify the best extraction conditions. The best conditions to maximize the extraction of total polyphenols were: ethanol, $50 \%$, for $47.5 \mathrm{~min}$. Although the yield of polyphenols was optimal at $65^{\circ} \mathrm{C}$, the maximum antioxidant capacity was achieved with an extraction temperature of $90{ }^{\circ} \mathrm{C}$. This study has identified the optimal conditions for the extraction of tea liquor with the best antioxidant properties. Epigallocatechin gallate, epicatechin gallate, epigallocatechin and
\end{abstract}


epicatechin were extracted from white tea at concentrations up to $29.6 \pm 10.6,5.40 \pm 2.09$, $5.04 \pm 0.20$ and $2.48 \pm 1.10 \mathrm{mg} / 100 \mathrm{~g}$.

Keywords: white tea; polyphenols; extraction; antioxidant; RSM; MECK

\section{Introduction}

Natural antioxidants are increasingly appreciated by consumers due to both their inherent positive effects [1] and to the possibility of using them as a source of natural additives to replace synthetic ones [2-4]. Tea is a natural plant that is a rich source of natural antioxidants and provides a high free radical scavenger activity $[5,6]$.

Tea, the infusion from Camellia sinensis (L), is one of the world's most widely consumed beverages [7,8]. Its medicinal properties have been widely explored [9]. In addition, its health promoting properties have been known from the early periods of the Chinese civilization, going back almost 5000 years [10].

Teas vary in properties depending on geographical origin, climatic conditions and processing methods [7], but in general, they can be classified into three types: unfermented (green and white teas), partially fermented (oolong tea) and completely fermented (black tea) [9,11]. White tea is the least processed tea. It is exclusively prepared from very young tea leaves and buds, which are harvested before being fully open and are processed by air drying [10]. This less extended processing confers to white tea its special and highly appreciated odour and flavour characteristics [12,13].

Some in vitro studies have reported and characterised the antioxidant activity of white tea $[11,14,15]$. Other studies have focused on its protective effects on live cells subject to induced oxidative stress [16-20]. Some of them have concluded that white tea extract is a neuroprotector, because it reduces the effect of hydrogen peroxide on cells [6]. This could be relevant to enhance the protection against neurodegenerative diseases, such as Alzheimer's or Parkinson's. Recent studies [21] suggest that the protective action of white tea in oxidative stress in vitro is related to the maintenance of the normal redox status of cells when they are susceptible to damage by free radicals.

The antioxidant capacity of white tea extracts, which can be measured in vitro by various assays, including oxygen radical absorbance capacity (ORAC), Trolox equivalent antioxidant capacity (TEAC), ferric reducing antioxidant power (FRAP) or diphenylpicrylhydrazyl assay (DPPH), among others [22-24]. This activity is linked to the high content of flavan-3-ols, which are also known as catechins. The major catechins present in tea are: epigallocatechin (EGC), catechin (C), epigallocatechin gallate (EGCG), epicatechin (EC) and epicatechin gallate (ECG) $[8,13,25]$.

These catechins have a high health benefits and industrial interest. They can be used in the pharmaceutical, cosmetic and food industries as a source of additives or as a source of antioxidants for functional foods $[4,9]$. As a result of these benefits, more effective extracts are a research focus of interest.

The main goal of this contribution is to determine the optimal extraction conditions of the main antioxidant compounds from white tea. In this study, the response surface methodology (RSM) was used 
for the optimization of extraction variables (time, temperature and $\%$ of ethanol) to enhance the yield of polyphenols and antioxidant activity [15,26,27].

\section{Experimental Section}

\subsection{Chemicals, Reagents and Equipment}

Methanol, ethanol, acetone, sodium carbonate, Folin-Ciocalteu reagent, sodium tetraborate, sodium phosphate dibasic and sodium hydroxide were of analytical grade from Panreac (Barcelona, Spain). Gallic acid (GA), rutin, 6-hydroxy-2,5,7,8-tetramethylchroman-2-carboxylic acid (Trolox), 2,4,6-tris (1-pyridyl)-5-triazine (TPTZ), phosphate buffered saline, ferric chloride, potassium persulfate, Tween 20, 2,2'-azino-bis(3-ethylbenzothiazoline-6-sulfonic acid) diammonium salt (ABTS), sodium dodecyl sulphate (SDS), (+)-catechin (C), (-)-epicatechin (EC), (-)-epigallocatechin (EGC), $(-)$-epicatechin gallate (ECG), (-)-epigallocatechin gallate (EGCG) and caffeine were purchased from Sigma-Aldrich Company Ltd. (Gillingham, UK). Ultrapure water obtained from a Milli-Q system from Millipore (Milford, MA, USA) was used throughout. Spectrophotometric measurements were taken on a Perkin Elmer FTIR spectrometer (Perkin Elmer, Paris, France). Fluorometric measurements were taken with a Florestar omega fluorimeter. Micellar electrokinetic chromatography (MECK) was carried out using the Packard 3DCE capillary electrophoresis system equipped with a diode-array detector from Agilent (Agilent Technologies, Santa Clara, CA, USA).

\subsection{Tea Samples and Preparation}

White tea was purchased from Manantial de Salud (Herbocat SL, Barcelona, Spain) and was stored at room temperature $\left(22 \pm 2{ }^{\circ} \mathrm{C}\right)$ in a desiccator. The samples were extracted by infusion.

Infusions were filtered through Whatman paper filters n.2 (GE Healthcare, Amersham Place, UK). All white tea extracts were protected from light and stored at $-20^{\circ} \mathrm{C}$ until needed.

\subsection{Determination of Total Phenolic Content}

The total phenol (TP) content of each extract was determined in duplicate by the Folin-Ciocalteu method according to Almajano et al. [16]. The mixture was allowed to stand in the dark at room temperature for $1 \mathrm{~h}$ and was finally diluted to an appropriate final volume with distilled water. Absorbance was measured at $765 \mathrm{~nm}$ against a blank containing distilled water instead of extract. Values were determined from a calibration curve prepared with gallic acid standard (GAE) $\left(2-14 \mathrm{mg} \cdot \mathrm{L}^{-1}\right.$ final concentration) and rutin $\left(1.25-15 \mathrm{mg} \cdot \mathrm{L}^{-1}\right.$ final concentration). Results are expressed as $\mathrm{mg}$ of gallic acid equivalents $\mathrm{g}^{-1}$ of dry weight (mg GAE/g DW) or $\mathrm{mg}$ of rutin equivalents/g of dry weight (mg rutin equivalents/g DW), respectively.

\subsection{Micellar Electrokinetic Capillary Chromatography (MECK)}

MECK is a separation mode of capillary electrophoresis (CE), which can be applied in the separation of neutral and charged compounds. The principle of separation is based on the differential migration of the ionic micelles and the bulk running buffer under electrophoresis conditions and on the interaction 
between the analyte and the micelle. The micelle is prepared by adding a surfactant, generally sodium dodecyl sulphate (SDS), into the running buffer. MECK is suitable for separation and quantification of natural antioxidants, because it is rapid, gives an efficient separation, uses minimum amounts of sample and reagents and is low cost [17,25,27-29].

MECK was carried out with the diode-array detector set at 200 and $260 \mathrm{~nm}$ to detect catechins and gallic acid simultaneously. A fused-silica capillary, with extended light path, $50 \mu \mathrm{m}$ i.d., $34 \mathrm{~cm}$ total length and $25.5 \mathrm{~cm}$ effective length, was used for the separation. The separation voltage was kept at $30 \mathrm{kV}$ with an intensity of $35 \mu \mathrm{A}$. The temperature of the capillary was set to $21^{\circ} \mathrm{C}$ and controlled with the help of a thermostat. The capillary was conditioned with $\mathrm{NaOH}(0.1 \mathrm{M}, 10 \mathrm{~min})$ followed by washing with an abundant flow of Milli-Q water and then of the buffer solution (155 min). Buffer ( $\mathrm{pH} 7)$ was prepared daily with $5 \mathrm{mM}$ sodium tetraborate, $60 \mathrm{mM}$ sodium phosphate dibasic and $50 \mathrm{mM}$ SDS.

All standard solutions (C, EC, GC, EG, EGCG) and sample extracts were injected in triplicate. A calibration curve prepared with standards was used to quantify the components $(\mathrm{mg} / \mathrm{L})$.

\subsection{Determination of Antioxidant Activity}

\subsubsection{Trolox Equivalent Antioxidant Capacity (TEAC)}

The method used was based on Re et al. [30]. 2,2'-Azino-bis(3-ethylbenzothiazoline-6-sulfonic acid) diammonium salt (ABTS, $7 \mathrm{mM}$ ) and potassium persulfate $(2.45 \mathrm{mM}$, final concentration) were dissolved separately in water, and then, the mixture was made up to volume in a $10 \mathrm{~mL}$ volumetric flask. The mixed solution was transferred to an amber bottle, covered with aluminium foil and allowed to stand at room temperature (RT) for $12-16 \mathrm{~h}$ in the dark. The ABTS ${ }^{\bullet+}$ solution was diluted with phosphate buffered saline (PBS) (pH 7.4, 1:100) and equilibrated at $30{ }^{\circ} \mathrm{C}$, to an absorbance of $0.7 \pm 0.02$ ) at $734 \mathrm{~nm}$, read in a Hewlett Packard 8452A diode array spectrophotometer (WaldBronn, Germany). An appropriate dilution of the extract was added to $\mathrm{ABTS}^{+}$solution in the proportion of 1:100. PBS (pH 7.4) was used as the blank. After mixing, the absorbance at $734 \mathrm{~nm}$ was measured immediately and, then, every minute for $5 \mathrm{~min}$. Duplicate determinations were made for triplicate extractions. The percentage inhibition was calculated from the absorbance values at $5 \mathrm{~min}$.

The relative change in sample absorbance was calculated according to the following equation:

$$
\Delta A_{\text {sample }}=\frac{A_{t=0(\text { sample })}-A_{t=5(\text { sample })}}{A_{t=0(\text { sample })}}-\frac{A_{t=0(\text { solvent })}-A_{t=5(\text { solvent })}}{A_{t=0(\text { solvent })}}
$$

The TEAC value was determined from a Trolox calibration curve (ranging from 1 to $10 \mu \mathrm{M}$ final concentration). Results are expressed as $\mu \mathrm{mol}$ of Trolox/g of DW.

\subsubsection{Oxygen Radical Antioxidant Capacity (ORAC)}

The ORAC method [28,31] is widely used in food science and biology. A stock solution of fluorescein (FL) was prepared by dissolving $2 \mathrm{mg}$ of FL in $100 \mathrm{~mL}$ of phosphate buffer (PBS) $75 \mathrm{mM}$ and pH 7. The stock solution was stored under refrigeration in the dark. The working FL solution (78 $\mathrm{nM})$ was prepared daily by adequate stock dilution in PBS. The 2,2'-Azobis(2-methylpropionamidine) 
dihydrochloride (AAPH)radical solution $(221 \mathrm{mM})$ was prepared daily by dilution in PBS. The standard used was Trolox solution.

The ORAC values were calculated using a regression equation between the Trolox concentration and the net area of the fluorescence decay curve (area under curve, AUC). ORAC was expressed as $\mu \mathrm{M}$ Trolox equivalents ( $\mu \mathrm{M}$ TE) and was calculated by applying the formula in Equation 2:

$$
A U C=\left(0.5+\left(\sum_{i=1}^{i=31} \frac{f_{i}}{f_{1}}\right)\right) \cdot C T
$$

where: $i$, the number of cycles; $f$, florescence units; $C T$, time of each cycle in minutes; in this case, $C T$ is $2 \mathrm{~min}$.

\subsection{Statistical Analysis}

The results obtained were analysed statistically using Minitab 5.1 for Windows (Minitab Inc., State Collage, PA, USA) and expressed as the means \pm standard deviations. Any significant difference between solvents and samples was determined by one-way analysis of variance (ANOVA, considering significant differences at $p<0.05$.

\subsection{Response Surface Methodology (RSM)}

The data were modelled and analysed by RSM, which is a collection of mathematical and statistical techniques suitable for problems in which a response of interest is influenced by several variables. It uses quantitative data from appropriate experimental designs to model and optimize the combination of factors that yield a desired response near the optimum [26].

In order to determine the optimum conditions for the extraction of tea polyphenols and to evaluated their activity with TEAC and ORAC, assays were performed using low and high levels for the independent variables, EtOH (\%), time ( $\mathrm{min})$ and temperature $\left({ }^{\circ} \mathrm{C}\right)$, in accordance with a factorial experimental design. The results of the preliminary trials of a two-level, three-variable full factorial design were taken into account, which involved three replicated runs. A two-level, three-factor and central composite design was chosen for this experimental design using the Minitab package for Windows software (Minitab, State Collage, PA, USA). Coded levels for independent variables are presented in Table 1.

Table 1. Variables and ranges used on the experimental design for the study of temperature $(T)$, time $(t)$ and $\%$ ethanol.

\begin{tabular}{cccc}
\hline \multirow{2}{*}{ Variables } & \multicolumn{3}{c}{ Range and Level } \\
\cline { 2 - 4 } & 1 & 0 & 1 \\
\hline Temperature $\left({ }^{\circ} \mathrm{C}\right)$ & 40 & 65 & 90 \\
Time $(\mathrm{min})$ & 5 & 47.5 & 90 \\
$\%$ EtOH & 0 & 50 & 100 \\
\hline
\end{tabular}


Coefficients of the full model were evaluated by regression analysis and tested for their significance. The non-significant coefficients $(p>0.05)$ were eliminated on the basis of $p$-values after examining the coefficients, and the models were finally refined. For the first-order model, we considered a $2^{3}$ factorial design augmented by three centre points. For the second-order model, we augmented the design with six points (star design). From the values (displayed in Table 1) and assuming a second order polynomial model, at least 17 experiments must be carried out to solve the matrix and the error evaluation. The resulting factorial central composite design for the two-level and three-factor scheme with 17 treatments in total is described in Table 2. The response surface values are the concentrations of resulting tea polyphenols, which are shown in the results section.

\section{Results and Discussion}

\subsection{Selection of Extraction Solvents}

It is reported by other researchers $[26,32,33]$ that ethanol and methanol were effective solvents for extracting phenolic compounds. For this study, only ethanol was used, since it is food-grade and also cheaper than methanol.

\subsection{Experimental Design}

The experimental design was carried out to evaluate the effects of temperature, solvent concentration and time on antioxidant extraction. The variables and ranges used are shown in Table 1. The $p$-value for each term analysed in each parameter is shown in Table 2 . The initial model and the final reducted model are shown in Table 3. The final reducted model, with all statistically significant terms, has a higher predicted $R^{2}$, which means that it is more reliable in estimating a response.

TP, ORAC, TEAC and caffeine show high number interactions with statistical significant terms $(p<0.05)$, and a good adjustment was obtained.

\subsection{Total Polyphenol Content}

The extraction efficiency of different concentrations of aqueous ethanol, temperature and time for the extraction of total polyphenols from white tea leaves was investigated using a central composite design. The total phenolic content in the white tea extracts ranged from 20.93 to $178.70 \mathrm{mg}$ as $\mathrm{GAE} / \mathrm{g}$ tea; see Table 2. It was observed that the best yield occurred with $47.5 \mathrm{~min}$ of extraction at $65{ }^{\circ} \mathrm{C}$, using $48 \%$ ethanol.

All of the linear coefficients and two quadratic coefficients $\left(\mathrm{EtOH}^{2}\right.$ and $\left.t^{2}\right)$ were significant. The final response model (using uncoded units) to predict the yield of tea polyphenols is shown in Equation 3:

$$
\mathrm{TP}=24.1036+2.3871 \mathrm{EtOH}+1.7821 t+0.6350 \mathrm{~T}-0.0270 \mathrm{EtOH}^{2}-0.0156 t^{2}
$$

where $T P$ is the response variable and $E t O H, t$ and $T$ are the values of the independent variables, namely the concentration of ethanol, extraction time and temperature, respectively. 
Table 2. Experimental design obtained and the experimental values obtained from the determination of total polyphenols, antioxidant capacity of the extracts assessed by TEAC and ORAC and polyphenol content.

\begin{tabular}{|c|c|c|c|c|c|c|c|c|c|c|c|c|}
\hline & \multirow{2}{*}{ Assay no } & \multirow{2}{*}{$\%$ EtOH } & \multirow{2}{*}{$t(\min )$} & \multirow{2}{*}{$T\left({ }^{\circ} \mathrm{C}\right)$} & \multicolumn{8}{|c|}{ Experimental Values } \\
\hline & & & & & $\mathbf{T P}$ & TEAC & ORAC & Caffeine & EGC & EGCG & ECG & EC \\
\hline \multirow{8}{*}{$\begin{array}{c}2^{3} \text { factorial } \\
\text { design }\end{array}$} & 1 & 0 & 5 & 40 & $62.4 \pm 3.1$ & $596 \pm 27$ & $710 \pm 83$ & $11.31 \pm 6.34$ & $1.19 \pm 0.53$ & $3.22 \pm 1.97$ & $0.46 \pm 0.26$ & $0.55 \pm 0.37$ \\
\hline & 2 & 96 & 5 & 40 & $20.9 \pm 2.2$ & $209 \pm 23$ & $437 \pm 102$ & $2.05 \pm 0.43$ & $1.86 \pm 0.05$ & $4.97 \pm 0.44$ & $1.08 \pm 0.08$ & $0.00 \pm 0.00$ \\
\hline & 3 & 0 & 90 & 40 & $95.7 \pm 4.1$ & $945 \pm 27$ & $1396 \pm 146$ & $21.08 \pm 0.90$ & $4.00 \pm 1.24$ & $9.97 \pm 3.58$ & $0.97 \pm 0.40$ & $1.86 \pm 0.53$ \\
\hline & 4 & 96 & 90 & 40 & $36.5 \pm 8.6$ & $348 \pm 92$ & $718 \pm 156$ & $3.68 \pm 1.42$ & $3.42 \pm 1.83$ & $10.50 \pm 5.76$ & $2.58 \pm 1.36$ & $0.33 \pm 0.31$ \\
\hline & 5 & 0 & 5 & 90 & $96.1 \pm 3.5$ & $1067 \pm 60$ & $1053 \pm 213$ & $28.16 \pm 2.13$ & $0.64 \pm 0.68$ & $1.92 \pm 1.04$ & $0.30 \pm 0.06$ & $0.14 \pm 0.05$ \\
\hline & 6 & 96 & 5 & 90 & $31.9 \pm 2.9$ & $341 \pm 32$ & $548 \pm 177$ & $3.52 \pm 0.28$ & $1.38 \pm 0.21$ & $1.21 \pm 0.78$ & $0.28 \pm 0.17$ & $0.22 \pm 0.06$ \\
\hline & 7 & 0 & 90 & 90 & $112.6 \pm 6.6$ & $1165 \pm 132$ & $1355 \pm 134$ & $27.84 \pm 1.88$ & $1.16 \pm 0.61$ & $3.55 \pm 2.44$ & $0.64 \pm 0.55$ & $0.45 \pm 0.45$ \\
\hline & 8 & 96 & 90 & 90 & $104.8 \pm 2.1$ & $1083 \pm 50$ & $1405 \pm 45$ & $9.18 \pm 0.39$ & $5.04 \pm 0.20$ & $10.90 \pm 4.97$ & $2.17 \pm 0.93$ & $1.29 \pm 0.17$ \\
\hline \multirow{6}{*}{ star design } & 9 & 0 & 47.5 & 65 & $94.8 \pm 7.9$ & $1042 \pm 82$ & $1244 \pm 60$ & $22.72 \pm 2.26$ & $0.80 \pm 0.68$ & $1.60 \pm 0.76$ & $0.18 \pm 0.08$ & $0.18 \pm 0.20$ \\
\hline & 10 & 96 & 47.5 & 65 & $113.3 \pm 24.9$ & $529 \pm 126$ & $906 \pm 285$ & $3.49 \pm 0.83$ & $4.79 \pm 2.28$ & $18.73 \pm 12.90$ & $4.66 \pm 3.15$ & $0.68 \pm 0.34$ \\
\hline & 11 & 48 & 5 & 65 & $148.5 \pm 6.8$ & $1777 \pm 25$ & $1914 \pm 171$ & $27.84 \pm 0.82$ & $1.71 \pm 1.60$ & $7.81 \pm 6.41$ & $1.25 \pm 1.07$ & $0.20 \pm 0.34$ \\
\hline & 12 & 48 & 90 & 65 & $138.1 \pm 25.6$ & $1433 \pm 221$ & $1749 \pm 296$ & $20.36 \pm 3.38$ & $1.06 \pm 0.32$ & $5.88 \pm 1.91$ & $0.90 \pm 0.43$ & $0.15 \pm 0.12$ \\
\hline & 13 & 48 & 47.5 & 40 & $144.4 \pm 16.0$ & $1466 \pm 124$ & $2387 \pm 467$ & $23.08 \pm 1.73$ & $2.01 \pm 0.52$ & $10.05 \pm 3.88$ & $1.71 \pm 0.89$ & $0.44 \pm 0.19$ \\
\hline & 14 & 48 & 47.5 & 90 & $173.4 \pm 7.9$ & $1940 \pm 117$ & $2174 \pm 245$ & $26.66 \pm 0.64$ & $4.01 \pm 0.20$ & $19.51 \pm 2.59$ & $3.20 \pm 0.44$ & $1.28 \pm 0.42$ \\
\hline \multirow{3}{*}{$\begin{array}{l}\text { central } \\
\text { design }\end{array}$} & 15 & 48 & 47.5 & 65 & $163.3 \pm 13.8$ & $1674 \pm 130$ & $1811 \pm 105$ & $25.08 \pm 0.11$ & $3.96 \pm 0.72$ & $21.25 \pm 6.78$ & $3.58 \pm 1.02$ & $1.77 \pm 0.40$ \\
\hline & 16 & 48 & 47.5 & 65 & $164.9 \pm 7.9$ & $1745 \pm 130$ & $1936 \pm 205$ & $26.85 \pm 1.72$ & $5.03 \pm 1.06$ & $27.45 \pm 7.87$ & $4.83 \pm 1.26$ & $1.31 \pm 0.20$ \\
\hline & 17 & 48 & 47.5 & 65 & $178.7 \pm 5.2$ & $1820 \pm 60$ & $2132 \pm 342$ & $27.48 \pm 2.37$ & $4.71 \pm 1.23$ & $29.60 \pm 10.60$ & $5.40 \pm 2.09$ & $2.48 \pm 1.10$ \\
\hline
\end{tabular}

Results are expressed as the mean of three replicates \pm standard deviation; TP, total polyphenols (mg gallic acid equivalents (GAE)/g); TEAC, Trolox equivalent antioxidant capacity ( $\mu \mathrm{M}$ $\mathrm{TE} / \mathrm{g}$ ); ORAC, oxygen radical antioxidant capacity ( $\mu \mathrm{M}$ Trolox equivalents (TE)/g tea); Caffeine, epigallocatechin (EGC), epigallocatechin gallate (EGCG), epicatechin (EC) and epicatechin gallate (ECG) expressed as $\mathrm{mg} / \mathrm{g}$. 
Table 3. The $p$-values for each of the constants in the equation of the mathematical model.

\begin{tabular}{|c|c|c|c|c|c|c|c|c|c|}
\hline & \multirow{3}{*}{ Term } & \multicolumn{8}{|c|}{$p$-Value } \\
\hline & & \multicolumn{8}{|c|}{ Response } \\
\hline & & TP & Caffeine & EGC & EGCG & ECG & EC & ORAC & TEAC \\
\hline \multirow{10}{*}{$\begin{array}{c}\text { Complete } \\
\text { Model }\end{array}$} & Constant & 0.986 & 0.562 & 0.230 & 0.742 & 0.496 & 0.150 & 0.003 & 0.174 \\
\hline & $\% \mathrm{EtOH}$ & 0.000 & 0.000 & 0.000 & 0.118 & 0.000 & 0.690 & 0.000 & 0.000 \\
\hline & $t(\min )$ & 0.008 & 0.156 & 0.002 & 0.007 & 0.003 & 0.007 & 0.170 & 0.416 \\
\hline & $T\left({ }^{\circ} \mathrm{C}\right)$ & 0.115 & 0.337 & 0.798 & 0.752 & 0.960 & 0.458 & 0.053 & 0.724 \\
\hline & $\% \mathrm{EtOH} \times \% \mathrm{EtOH}$ & 0.000 & 0.000 & 0.610 & 0.045 & 0.786 & 0.270 & 0.000 & 0.000 \\
\hline & $t(\min ) \times t(\min )$ & 0.000 & 0.550 & 0.004 & 0.002 & 0.004 & 0.000 & 0.013 & 0.130 \\
\hline & $T \times T$ & 0.157 & 0.959 & 0.470 & 0.717 & 0.550 & 0.563 & 0.049 & 0.958 \\
\hline & $\mathrm{EtOH} \times t(\min )$ & 0.204 & 0.692 & 0.490 & 0.590 & 0.715 & 0.175 & 0.740 & 0.133 \\
\hline & $\% \mathrm{EtOH} \times T\left({ }^{\circ} \mathrm{C}\right)$ & 0.344 & 0.004 & 0.720 & 0.730 & 0.209 & 0.269 & 0.276 & 0.538 \\
\hline & $t \times T$ & 0.184 & 0.269 & 0.400 & 0.940 & 0.385 & 0.980 & 0.671 & 0.220 \\
\hline \multirow{10}{*}{$\begin{array}{c}\text { Reducted } \\
\text { Model }\end{array}$} & Constant & 0.038 & 0.003 & 0.027 & 0.344 & -0.771 & 0.069 & 0.001 & 0.003 \\
\hline & $\% \mathrm{EtOH}$ & 0.000 & 0.000 & 0.017 & 0.060 & 0.016 & - & 0.000 & 0.000 \\
\hline & $t(\min )$ & 0.000 & 0.000 & 0.096 & 0.000 & 0.130 & 0.041 & 0.006 & 0.000 \\
\hline & $T\left({ }^{\circ} \mathrm{C}\right)$ & 0.000 & 0.000 & - & - & - & - & 0.089 & 0.000 \\
\hline & $\% \mathrm{EtOH} \times \% \mathrm{EtOH}$ & 0.000 & 0.000 & - & 0.018 & - & - & 0.000 & 0.000 \\
\hline & $t(\min ) \times t(\min )$ & - & - & 0.001 & 0.000 & 0.001 & 0.000 & 0.052 & - \\
\hline & $T \times T$ & 0.000 & - & - & - & - & - & - & - \\
\hline & $\mathrm{EtOH} \times t(\mathrm{~min})$ & - & - & - & - & - & - & - & - \\
\hline & $\% \mathrm{EtOH} \times T\left({ }^{\circ} \mathrm{C}\right)$ & - & 0.003 & - & - & - & - & - & - \\
\hline & $t \times T$ & - & - & - & - & - & - & - & - \\
\hline
\end{tabular}

- : Term not applied in the Model

The coefficient of determination in a multiple regression equation measures the strength of the relationship between the independent variables and the (dependent) response. The value of the determination coefficient for the equation for tea polyphenols is $R^{2}=0.873$, which indicates that only $13 \%$ of the total variation is not explained by the model.

Focusing on the RSM (represented in Figure 1A), it can deduced that the TP dependency is quadratic, and the optimal results could be obtained by extracting with $45 \%$ ETOH for $57 \mathrm{~min}$, at $90{ }^{\circ} \mathrm{C}$.

The results of this study are different from those of other authors; Venditti et al. [10] obtained significantly higher values in white tea after steeping in cold water (RT) for two hours. This study found that extraction of polyphenols was poor for water and aqueous ethanol at $40{ }^{\circ} \mathrm{C}$.

Acid $\mathrm{pH}$ is reported to improve polyphenol extraction [14,15,17,34]. Zimmerman [34] reported that at $\mathrm{pH}=3$, ECG extraction increased $20 \%$ and suggested that this may be due to two possible mechanisms. At a low $\mathrm{pH}$, either the diffusion of flavonoids from the leaf into the aqueous phase increased or degradation of the leaf structure occurred, permitting better accessibility of the solvent to the leaf components. However, when lemon juice was used to reduce the $\mathrm{pH}$, the antioxidant capacity of the lemon juice bioactive compounds was not considered [35,36]. 


\subsection{Polyphenol and Caffeine Composition}

Caffeine, EGC, EGCG, ECG, EC, catechin and gallic acid content were analysed by MECK. Catechin and gallic acid were not detected. All results obtained are shown in Table 2.

Caffeine shows a final response model (Equation 4) with good adjustment $\left(R^{2}=0.89\right)$ in the model.

$$
\text { Caffeine }=7.93192+0.41115 E t O H+0.21984 T-0.00481 E t O H^{2}-0.00166 E t O H \times T
$$

The caffeine extracted was in the range of $2.05-28.3 \mathrm{mg} / \mathrm{g}$ dry tea. The minimum values were observed in samples extracted with a high ethanol concentration. This is consistent with the low polarity of the caffeine molecule. There is no literature about the caffeine content of white tea samples.

EC, ECG and EG have a reduce number of terms and interactions with statistical significant $p$-values (Table 3). They have an equation with low $R^{2}$. This fact suggested that the TP model responds to the synergic effect of all catechins contained in the sample.

Despite this bad adjustment, experimental results (Table 2) show that tea ECG content was in the range from 0.64 to $5.04 \mathrm{mg} / \mathrm{g}$ GAE. Lopez et al. [37], obtained similar ECG values $(7.95 \mathrm{mg} / \mathrm{g}$ of tea) using an acid extraction method. Rusak et al. [13] reported a very high ECG content ( $42.3 \mathrm{mg} / \mathrm{g}$ of tea) after acid extraction and HPLC analysis. The latter author obtained $34.4 \mathrm{mg}$ ECG/g dry tea using 40\% ethanol for $30 \mathrm{~min}$ and $12.9 \mathrm{mg} / \mathrm{g}$ dry tea using $70 \%$ ethanol.

The EGC yield was $1.21-29.60 \mathrm{mg} / \mathrm{g}$ dry tea. The maximum yield was obtained with ethanol between $48 \%$ and $96 \%$ with an extraction time of $47.5 \mathrm{~min}$ and a temperature range of $56-90{ }^{\circ} \mathrm{C}$. Rusak et al. [13] reported a range between 40.2 and $154 \mathrm{mg}$ of EGC/g of dry white tea in bags and a range between 38.9 and $129 \mathrm{mg} / \mathrm{g}$ of $\mathrm{EGC} / \mathrm{g}$ of dry tea in loose leaves analysed by HPLC. Lopez et al. [37] reported $11.1 \mathrm{mg} \mathrm{EGC/g}$ white tea, which is well within the range that was found by MECK analysis in this study.

The ECG content of the extracts corresponded to values between 0.18 and $5.40 \mathrm{mg}$ ECG as GAE/g tea. Values reported by Lopez et al. [37] (3.19 mg/g dry tea) extracted from acidified samples were within this range. However, Rusak et al.[13] reported that $36.6 \mathrm{mg}$ ECG as GAE/g dry white tea was extracted using 40\% ethanol for a 15-30 min extraction time.

In EC analysis, a maximum extraction of $2.48 \mathrm{mg} / \mathrm{g}$ GAE was obtained in this study, which is similar to the value reported by Lopez et al. [37] $(2.13 \mathrm{mg} / \mathrm{g})$.

\subsection{Antioxidant Capacity}

The antioxidant activity of the different white tea infusions was assessed by the TEAC and ORAC assays. Some authors have shown significant differences in free radical scavenging activity according to the assay method used [23,38] and have reported that the TEAC assay is simpler and cheaper than the ORAC assay, but may give an underestimate of the antioxidant capacity. Tabart et al. [23] proposed that the mean of the values obtained using four different tests should be used.

A comparison between the two methods used in this study is presented, and the results are analysed using RSM. 


\subsubsection{TEAC}

The contour plot (Figure 1B) shows that the TEAC values were highest for EtOH concentrations between $40 \%$ to $50 \%$. The extract with the maximum TEAC value was obtained with $43.7 \%$ EtOH for $90 \mathrm{~min}$. Surface plots shows that there was a quadratic dependence on $\% \mathrm{EtOH}$ and a linear dependence on extraction time. All of the linear coefficients were again significant, but just one quadratic coefficient $\left(\mathrm{EtOH}^{2}\right)$ was included. The final response model (using uncoded units) to predict TEAC is shown in Equation 5:

$$
T E A C=325.540+33.821 E t O H+2.314 t+8.126 T-0.384 E t O H^{2}
$$

where TEAC is the response variable. The value of the determination coefficient for the equation is $R^{2}=0.91$ (only about $9 \%$ of the total variation is not explained by the model), so it can be concluded that there is a very good correlation between TEAC and the independent variables.

Samples 14 and 17, which had the highest TEAC values, had the highest TP values (Table 2). The polyphenols present were rich in EGCG, with moderate concentrations of ECG and EGC and a low concentration of EC (see Table 3). Salah et al. [39] reported that the relative antioxidant activity of the tea catechins assessed by the TEAC assay was in the order ECG $>$ EGCG $>$ EGC $>$ EC, so it is clear that ECG and EGCG made important contributions to the antioxidant capacity.

\subsubsection{ORAC}

For assessment of antioxidant capacity by the ORAC assay, only two linear coefficients (EtOH and $t$ ) and one quadratic coefficient $\left(\mathrm{EtOH}^{2}\right)$ were significant. The final response model (using uncoded units) to predict ORAC is defined in Equation 6:

$$
O R A C=932.682+38.017 E t O H+4.615 t-0.415 E{ }^{2} H^{2}
$$

where ORAC is the response variable. The value of the determination coefficient for the equation is $R^{2}=0.791$, which indicates that less than $21 \%$ of the total variation was not explained by the model.

\subsection{Correlation between TP, TEAC and ORAC}

The study of the correlation between experimental data obtained in TP, TEAC and ORAC was also evaluated. Several authors have reported correlations between the results found for radical scavenging activity assessed by the TEAC and ORAC methods [39]. The results of this study show a correlation between TP, TEAC and ORAC values (Figure 2). The best correlation is that between total polyphenols (TP) and TEAC values $\left(R^{2}=0.90\right)$.

The correlation between TP and the ORAC values is not so good $\left(R^{2}=0.86\right)$. The most likely reason for this is that the TEAC assay only measures single electron transfer (SET) and can only measure the extent of inhibition by antioxidants. ORAC combines the time and magnitude of the inhibition, so the effects of slow reacting and fast reacting antioxidants differ in this assay, but not in the TP or TEAC assays.

All three variables in the extraction process had a significant effect on the polyphenols and TEAC value. EtOH and time had a much greater effect on the ORAC value, while temperature had less effect. 
Figure 1 displays the surface plots of RSM, in which the fitted responses were plotted against changes in the factors, $\mathrm{EtOH}$ and time, whereas the temperature was held at three different levels $\left(40{ }^{\circ} \mathrm{C}, 65^{\circ} \mathrm{C}\right.$ and $\left.90{ }^{\circ} \mathrm{C}\right) . \mathrm{EtOH}$ and time are represented on the $x$-axis, while TP, TEAC and ORAC are shown on the $y$-axis.

Figure 1. Response surface plots (left) and contour plots (right) showing the effect of ethanol concentration \% in white tea extractions and the relations with antioxidant capacity evaluated by TP, TEAC and ORAC. (A) Response surface methodology (RSM) for TP and EtOH, (B) RSM for TEAC and ETOH and (C) RSM for ORAC and EtOH.

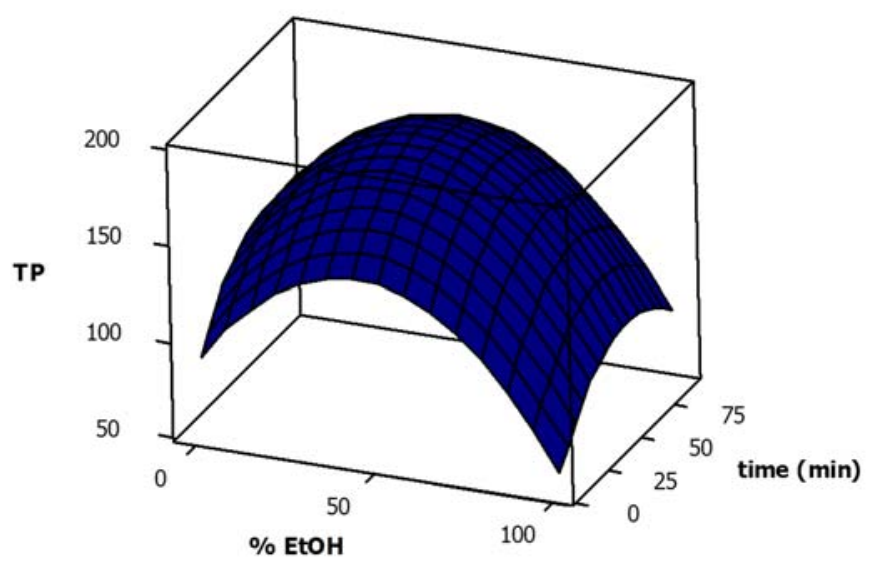

(A)

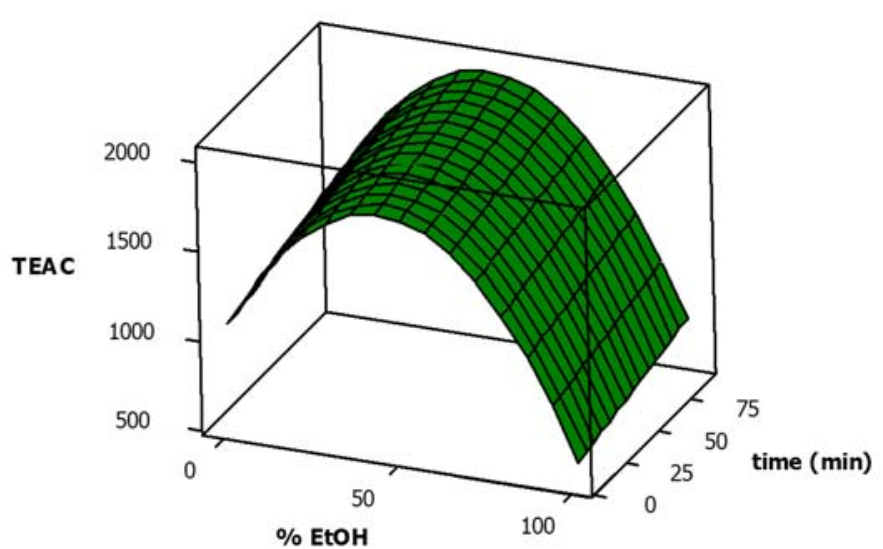

(B)

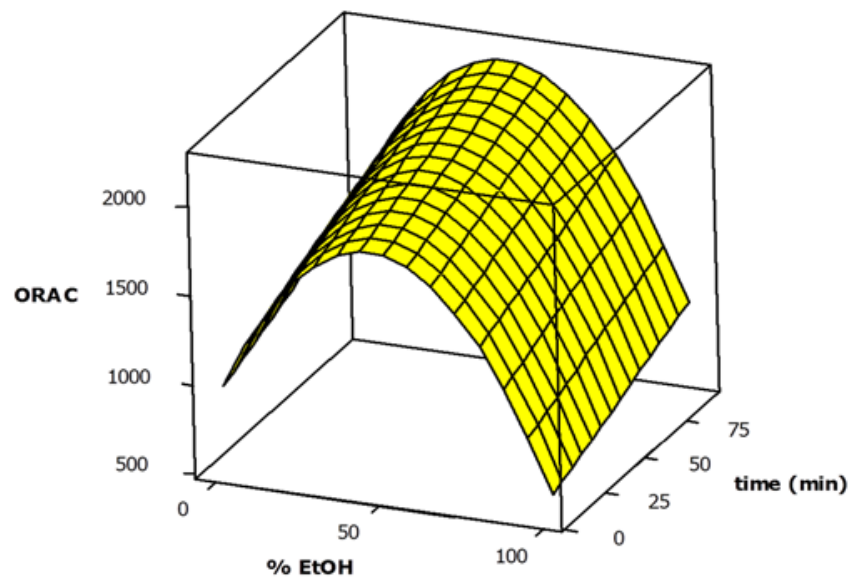

(C)
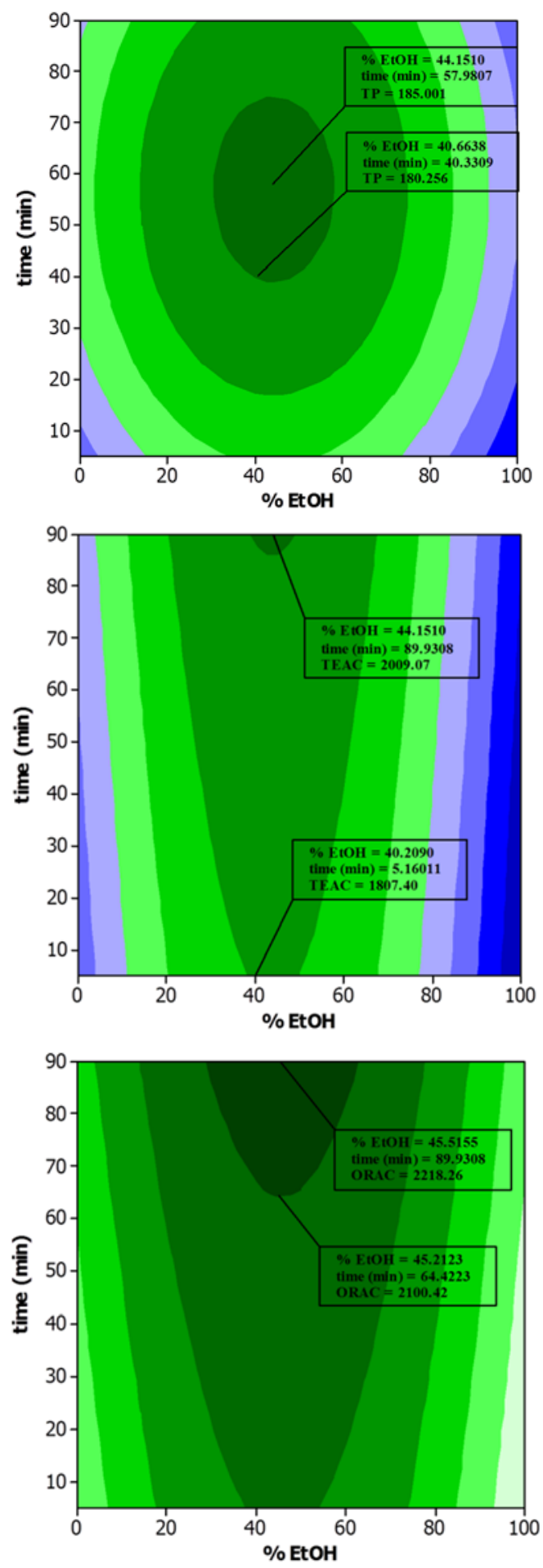
Figure 2. Correlation between TEAC, ORAC and total polyphenols (TP). (A) Correlation between TEAC and TP, (B) ORAC and TP and (C) ORAC and TEAC.

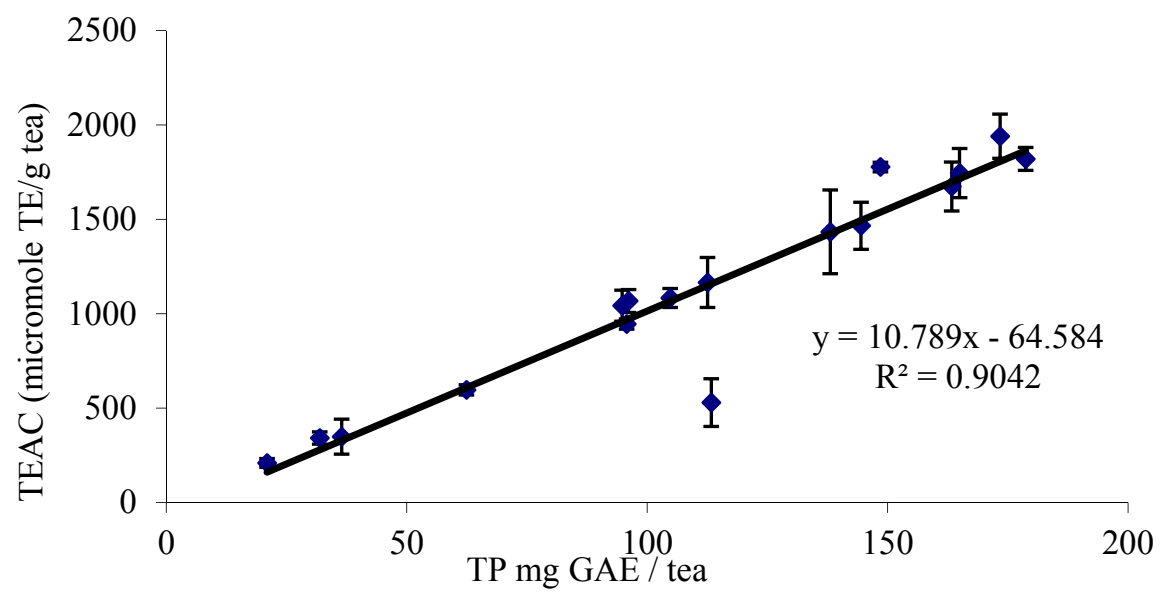

(A)

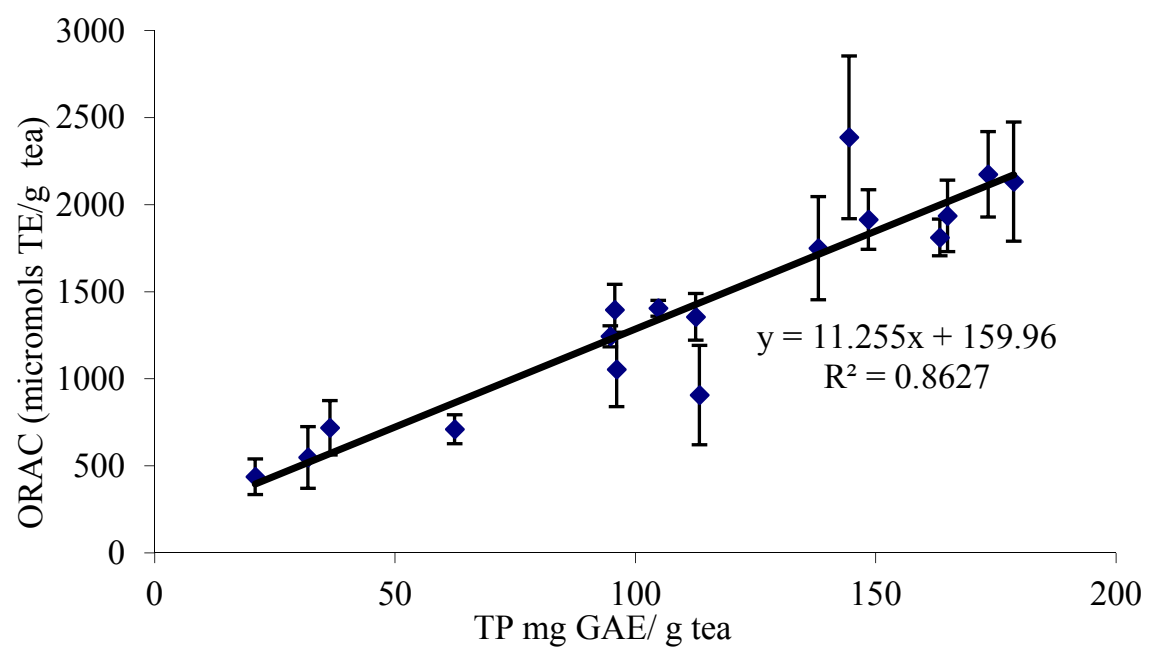

(B)

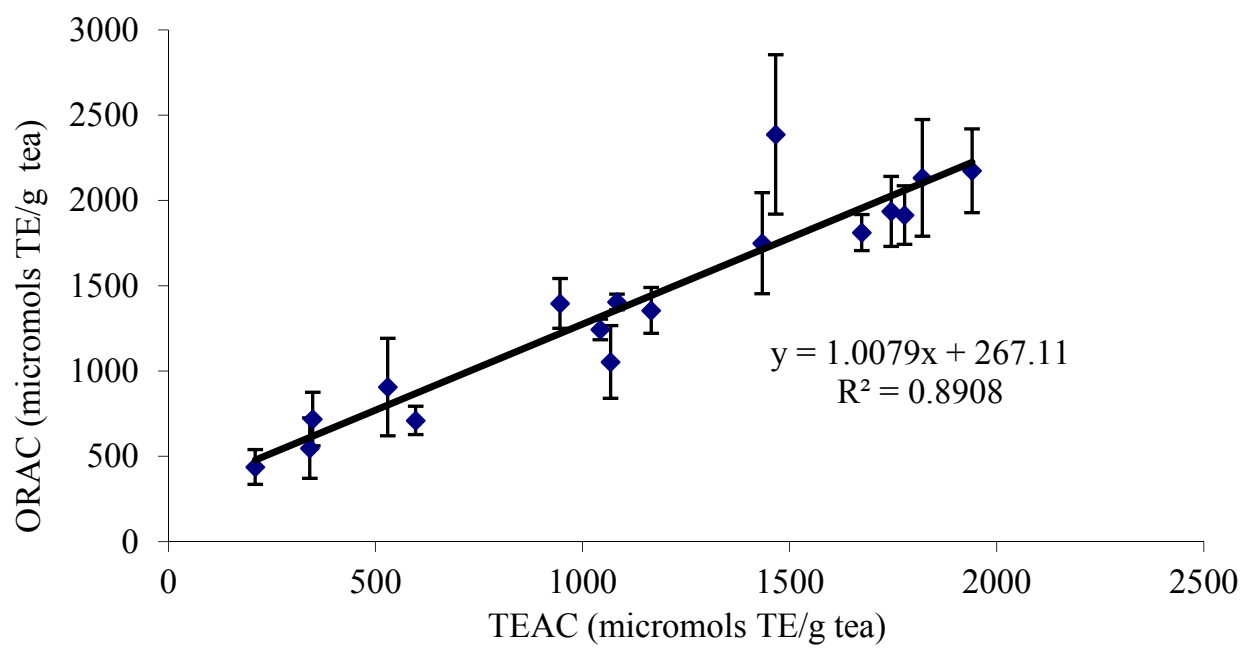

(C) 
The optimal conditions for the extraction of tea polyphenols predicted by the equation were: $\mathrm{EtOH}=45 \%, t=57 \mathrm{~min}$ and $T=90^{\circ} \mathrm{C}$. Likewise, the conditions for extracts with optimal TEAC values predicted by the equation were: $\mathrm{EtOH}=40 \%, t=90 \mathrm{~min}$ and $\mathrm{T}=90^{\circ} \mathrm{C}$. Finally, the conditions for extracts with optimal ORAC values predicted by the equation were: $\mathrm{EtOH}=40 \%-60 \%$ and $t=60 \mathrm{~min}$, with no significant effect of temperature.

\section{Conclusions}

The highest amounts of polyphenols (both individually and as determined by the Folin-Ciocalteu assay) were extracted at intermediate values of the conditions studied (about 48\% ethanol, $47.5 \mathrm{~min}$ and $65{ }^{\circ} \mathrm{C}$ ). The TP values correlated with antioxidant capacity determined by both the ORAC and TEAC assays, although the best temperature for the extraction of radical scavenging components assessed by the TEAC assay was $90^{\circ} \mathrm{C}$. Time is the factor that was less important, in the ranges studied, and $\% \mathrm{EtOH}$ had the greatest influence. This study has identified optimal conditions for the extraction of tea liquor with the best antioxidant properties.

\section{Acknowledgments}

This project was supported by the Agencia d'Ajuts Universitaris i de Recerca (AGAUR) (Catalonia, Spain). The authors thanks to Technical University from Catalonia for their support in this research.

\section{Author Contributions}

María Pilar Almajano and Francisca Pérez-Llamas conceived and designed the study. Mónica Blanco performed the statistical analysis. Sara Peiró and Francisco Segovia did the experimental work, analysed the data and interpreted results. Sara Peiró wrote the paper and Michael H. Gordon helped with English, with concepts and revised it critically. Finally, María Pilar Almajano reviewed all the manuscript and the final version to be submitted.

\section{Conflicts of Interest}

The authors declare no conflict of interest.

\section{References}

1. Oh, J.; Jo, H.; Cho, A.R.; Kim, S.; Han, J. Antioxidant and antimicrobial activities of various leafy herbal teas. Food Control 2013, 31, 403-409.

2. Gülçin, I. Antioxidant activity of food constituents: An overview. Arch. Toxicol. 2012, 86, 345-391.

3. Silva-Weiss, A.; Ihl, M.; Sobral, P.J.A.; Gómez-Guillén, M.C.; Bifani, V. Natural Additives in Bioactive Edible Films and Coatings: Functionality and Applications in Foods. Food Eng. Rev. 2013, 5, 200-216.

4. Perumalla, A.V.S.; Hettiarachchy, N.S. Green tea and grape seed extracts-Potential applications in food safety and quality. Food Res. Int. 2011, 44, 827-839. 
5. Gramza, A.; Korczak, J. Tea constituents (Camellia sinensis L.) as antioxidants in lipid systems. Trends Food Sci. Technol. 2005, 16, 351-358.

6. Almajano, M.P.; Carbo, R.; Jimenez, J.A.L.; Gordon, M.H. Antioxidant and antimicrobial activities of tea infusions. Food Chem. 2008, 108, 55-63.

7. Cabrera, C.; Artacho, R.; Giménez, R. Beneficial effects of green tea-A review. J. Am. Coll. Nutr. 2006, 25, 79-99.

8. Sharangi, A.B. Medicinal and therapeutic potentialities of tea (Camellia sinensis L.)-A review. Food Res. Int. 2009, 42, 529-535.

9. Moderno, P.M.; Carvalho, M.; Silva, B.M. Recent patents on Camellia sinensis: Source of health promoting compounds. Recent Pat. Food Nutr. Agric. 2009, 1, 182-192.

10. Venditti, E.; Bacchetti, T.; Tiano, L.; Carloni, P.; Greci, L.; Damiani, E. Hot vs. cold water steeping of different teas: Do they affect antioxidant activity? Food Chem. 2010, 119, 1597-1604.

11. Hilal, Y.; Engelhardt, U. Characterisation of white tea-Comparison to green and black tea. $J$. Verbrauch. Lebensm. 2007, 2, 414-421.

12. Müller, N.; Ellinger, S.; Alteheld, B.; Ulrich-Merzenich, G.; Berthold, H.K.; Vetter, H.; Stehle, P. Bolus ingestion of white and green tea increases the concentration of several flavan-3-ols in plasma, but does not affect markers of oxidative stress in healthy non-smokers. Mol. Nutr. Food Res. 2010, $54,1636-1645$.

13. Rusak, G.; Komes, D.; Likić, S.; Horžić, D.; Kovač, M. Phenolic content antioxidative capacity of green and white tea extracts depending on extraction conditions and the solvent used. Food Chem. 2008, 110, 852-858.

14. Unachukwu, U.J.; Ahmed, S.; Kavalier, A.; Lyles, J.T.; Kennelly, E.J. White and Green Teas (Camellia sinensis var. sinensis): Variation in Phenolic, Methylxanthine, and Antioxidant Profiles. J. Food Sci. 2010, 75, C541-C548.

15. Komes, D.; Belščak-Cvitanović, A.; Horžić, D.; Rusak, G.; Likić, S.; Berendika, M. Phenolic composition and antioxidant properties of some traditionally used medicinal plants affected by the extraction time and hydrolysis. Phytochem. Anal. 2011, 22, 172-180.

16. Almajano, M.P.; Vila, I.; Gines, S. Neuroprotective effects of white tea against oxidative stress-induced toxicity in striatal cells. Neurotox. Res. 2011, 20, 372-378.

17. Lopez, V.; Isabel Calvo, M. White Tea (Camellia sinensis Kuntze) Exerts Neuroprotection against Hydrogen Peroxide-Induced Toxicity in PC12 Cells. Plant Foods Hum. Nutr. 2011, 66, 22-26.

18. Thring, T.S.A.; Hili, P.; Naughton, D.P. Antioxidant and potential anti-inflammatory activity of extracts and formulations of white tea, rose, and witch hazel on primary human dermal fibroblast cells. J. Inflamm. 2011, 8, 27.

19. Yen, W.-J.; Chyau, C.-C.; Lee, C.-P.; Chu, H.-L.; Chang, L.-W.; Duh, P.-D. Cytoprotective effect of white tea against $\mathrm{H}_{2} \mathrm{O}_{2}$-induced oxidative stress in vitro. Food Chem. 2013, 14, 4107-4114.

20. Camouse, M.M.; Domingo, D.S.; Swain, F.R.;Conrad, E.P.; Matsui, M.S.; Maes, D.; Declercq, L.; Cooper, K.D.; Stevens, S.R.; Baron, E. Topical application of green and white tea extracts provides protection from solar-simulated ultraviolet light in human skin. Exp. dermatol. 2009, 18, 522-526.

21. Dias, R.; Alves, M.G.; Socorro, S.; Silva, B.M.; Oliveira, P.F. White Tea as a Promising Antioxidant Medium Additive for Sperm. J. Agric. Food Chem. 2014, 62, 608-617. 
22. Hengst, C.; Werner, S.; Müller, L.; Fröhlich, K.; Böhm, V. Determination of the antioxidant capacity: Influence of the sample concentration on the measured values. Eur. Food Res. Technol. 2009, 230, 249-254.

23. Tabart, J.; Kevers, C.; Pincemail, J.; Defraigne, J.-O.; Dommes, J. Comparative antioxidant capacities of phenolic compounds measured by various tests. Food Chem. 2009, 113, 1226-1233.

24. Rusaczonek, A.; Swiderski, F.; Waszkiewicz-Robak, B. Antioxidant Properties of Tea and Herbal Infusions-A Short Report. Pol. J. Food Nutr. Sci. 2010, 60, 33-35.

25. Peres, R.G.; Tonin, F.G.; Tavares, M.F.M.; Rodriguez-Amaya, D.B. Determination of catechins in green tea infusions by reduced flow micellar electrokinetic chromatography. Food Chem. 2011, 127, 651-655.

26. Sun, Y.; Liu, D.; Chen, J.; Ye, X.; Yu, D. Effects of different factors of ultrasound treatment on the extraction yield of the all-trans- $\beta$-carotene from citrus peels. Ultrason. Sonochem. 2011, 18, 243-249.

27. Terabe, S. Capillary separation: Micellar electrokinetic chromatography. Annual Rev. Anal. Chem. 2009, 2, 99-120.

28. Prior, R.L.; Wu, X.L.; Schaich, K. Standardized methods for the determination of antioxidant capacity and phenolics in foods and dietary supplements. J. Agric. Food Chem. 2005, 53, 4290-4302.

29. Herrero, M.; Ibáñez, E.; Cifuentes, A. Analysis of natural antioxidants by capillary electromigration methods. J. Sep. Sci. 2005, 28, 883-897.

30. Re, R.; Pellegrini, N.; Proteggente, A.; Pannala, A.; Yang, M.; Rice-Evans, C. Antioxidant activity applying an improved ABTS radical cation decolorization assay. Free Radic. Biol. Med. 1999, 26, 1231-1237.

31. Ou, B.; Hampsch-Woodill, M.; Prior, R.L. Development and validation of an improved oxygen radical absorbance capacity assay using fluorescein as the fluorescent probe. J. Agric. Food Chem. 2001, 49, 4619-4626.

32. Ferruzzi, M.G.; Green, R.J. Analysis of catechins from milk-tea beverages by enzyme assisted extraction followed by high performance liquid chromatography. Food Chem. 2006, 99, 484-491.

33. Mariya John, K.M.; Vijayan, D.; Raj Kumar, R.; Premkumar, R. Factors influencing the efficiency of extraction of polyphenols from young tea leaves. Asian J. Plant Sci. 2006, 5, 123-126.

34. Zimmermann, B.F.; Gleichenhagen, M. The effect of ascorbic acid, citric acid and low $\mathrm{pH}$ on the extraction of green tea: How to get most out of it. Food Chem. 2011, 124, 1543-1548.

35. Del Río, J.A.; Fuster, M.D.; Gómez, P.; Porras, I.; García-Lidón, A.; Ortuño, A. Citrus limon: A source of flavonoids of pharmaceutical interest. Food Chem. 2004, 84, 457-461.

36. González-Molina, E.; Moreno, D.A.; García-Viguera, C. Genotype and harvest time influence the phytochemical quality of Fino lemon juice (Citrus limon (L.) Burm. F.) for industrial use. J. Agric. Food Chem. 2008, 56, 1669-1675.

37. López, M.D.M.C.; Vilariño, J.M.L.; Rodríguez, M.V.G.; Losada, L.F.B. Development, validation and application of Micellar Electrokinetic Capillary Chromatography method for routine analysis of catechins, quercetin and thymol in natural samples. Microchem. J. 2011, 99, 461-469. 
38. Zulueta, A.; Esteve, M.J.; Frasquet, I.; Frígola, A. Vitamin C, vitamin A, phenolic compounds and total antioxidant capacity of new fruit juice and skim milk mixture beverages marketed in Spain. Food Chem. 2007, 103, 1365-1374.

39. Salah, N.; Miller, N.J.; Paganga, G.; Tijburg, L.; Bolwell, G.P.; Rice-Evans, C. Polyphenolic flavanols as scavengers of aqueous phase radicals and as chain-breaking antioxidants. Arch. Biochem. Biophys. 1995, 322, 339-346.

(C) 2014 by the authors; licensee MDPI, Basel, Switzerland. This article is an open access article distributed under the terms and conditions of the Creative Commons Attribution license (http://creativecommons.org/licenses/by/4.0/). 